[Conclnded from SUPPLËmENT No. 142\%, page 22862.] THE KRUPP WORKS AT ESSEN.-II.*

By ay allen Willey.

Bотн Friedrich and his son, Alfred Krupp, believed that a successful industry should own not only the terial forming the base, and this is why the coal an ore mines in connection with the blast furnaces form such a notable adjunct of the enterprises under consideration. One of the principal coal mines is located
practically on the site of the Essen works, the other practically on the site of the Essen works, the other
two being situated near Bochum. In all they com two being situated near Bochum. In all they com-
prise seven working pits, of which three are at Essen. prise seven working pits, of which three are at Essen.
The former have a maximum depth of 1,700 feet, and at present no less than ten veins of coal are being
worked on two levels, the veins varying from $21 / 2$ to hand mining, but the works are equipped with both overground and underground draining machinery, a hydraulic air compressor for operating ventilators,
while a separating and washing floor is installed, while a separating and washing floor is installed,
which has a capacity of 100 tons hourly. The worlswhich has a capacity of 100 tons hourly. The worl-
ings near Bochum contain thirty veins with a total thickness of 112 feet. They are much more extensive
than the pits at Essen, and furnish most of the total output of the Krupp mines, which represent nearly $1,500,000$ tons yearly. They are also provided with well as hydraulic air compressors, which have a capacity of 10,000 cubic feet hourly, in addition to four
ventilators and four separation plants, treating 200 ventilators and four separation plants, treating 200
tons an hour. In connection with the mines are sets tons an hour. In connection with the mines are sets
of coke ovens having a total daily output of 700 tons These are of the vertical type served from above, bu ducts, such as is installed in most of the modern ovens deposits produce annually about 520.000 tons. They include, as stated, 667 different allotments, producing
hematite and red ore ag well as manganese. The hematite and red ore ag well as manganese. The
Krupp interest in the Spanish mines is held under the title of the Orconera Iron Ore Company, and a line of steamships owned by the Krupps is devoted to its transportation to Germany.

The blast furnace capacity is not as large as might be imagined when contrasted with the capacity of the side walls of granite, and are closed by pontoons. Four are inclosed with glass roofs and sides, but are suffciently lofty to allow the use of overhead traveling terial can be transferred in this manner without de-
lay. One of the most extensive is so arranged that a lay. One of the most extensive is so arranged that a
flotilla of four or five torpedo boats of the ordinary
size can be constructed at once if desired.

The mechanical equipment is on a par with the Essen works in design and capacity. The various de partments, such as the forging, fitting, and bending shops, the plate yards, mold loft, joiner and paint
shops, are provided with a complete outfit of steam shops, are provided with a complete outfit of steam
and electrically-driven machinery. Other notable diand electrically-driven machinery. Other notable di-
visions are a plant for model making, also for the visions are a plant for model making, also for the
manufacture of cylindrical and water-tube boilers, copper-forging plant, and a plant for testing marine 1,000 machine tools in addition to 10 steam hammers and 72 hydraulic and electric cranes. The electric power is distributed by a series of 260 dynamos and motors. It is at the Germania yard that the cele-
brated 150-ton crane has been Installed for placing brated 150 -ton crane has been Installed for placing
ordnance, engines, and other-heavy weights on battleordnance, engines, and ot
ships and merchantmen.

ships and merchantmen.
Reference has already been made to the importance Reference has already been made to the importance
of this plant in the construction of war vessels. Among the notable craft completed are four battleships for the German navy, including the "Wörth," of 10,000 tons, the "Zähringen," of 11,800 tons, and another
ship recently placed in commission of 13,000 tons. A number of the principal naval vessels, such as the battleship "Baden," have been rebuilt. Recent addi-
tions to the fleet of German cruisers, such as the tions to the fleet of German cruisers, such as the
"Prinzess Wilhelm," "Nymphe," and "Amazone," were constructed in these slips. One of the most notable pany secured the contract from the Russian govern$m \in n t$ in competition with several other German firms as well as Italian and Russian yards. This cruiser,
which is of 6,000 tons, was not only built for speed, but to carry unusually powerful batteries. She presents a peculiar appearance from the fact that sh tained a speed of no less than 24 knots an hour with her triple screws, one knot more than the required rate, developing 19,999 horse power. Among the ad-
ditions to Germany's merchantmen built at the Ger- posite vessels, and in the under-water fittings of iron and steel ships.

3 . The decay of the brazing-metal in copper steam 4. The deterioration, as distinguished from oxida tion, of cast iron used for parts of marine engines, and also for other appliances which were in frequen
or continuous contact with sea-water. 5 . The decay of some propellers made of the patent bronzes when fitted to copper-bottomed vessels. In the case of condenser-tubes it was apparent that some of the metal became eaten away into holes, while in the other cases mentioned the metal appeared to retain its original form. The

Chemical analysis of the decayed portions showed that a change had occurred in the composition of the metal, but did not explain why its strength and properties were so completely modied. It showed that in copper-zinc alloys the process had been mainly one of part of the iron, and possibly also of the manganose had disappeared, the whole of the graphitic carbon remaining.

Although the decay of copper-zinc alloys had been known for many years, the first published research into its cause appears to have been made by Prof. Arnold, who in 1898, investigated the case of the failure of a marine boiler steam-pipe. He pointed out
that the brazing-metal of the pipe, when microscopically examined, was seen to possess a duplex structure ally examined, was seen to possess a duplex structure,
similar to that of Muntz metal, both constituents being definite. chemical compounds of copper and zinc, but one richer in copper than the other; and he attributed the decial to local galvanic action set up bet ween these constituents, whereby in the first stage, the one less rich in copper becomes dezinckified, and subsequently becoming a spongy mass of copper.

Microscopic study showed that the Muntz metal tubeplates, rods, etc., had been subject to similar decay to that pointed out by Prof. Arnold, and also that in the
decay of cast iron the complexity of structure doubtless along the lines of the graphite plates and leaving the phosphide eutectic portions till the last.

This explanation of local galvanic action, however,

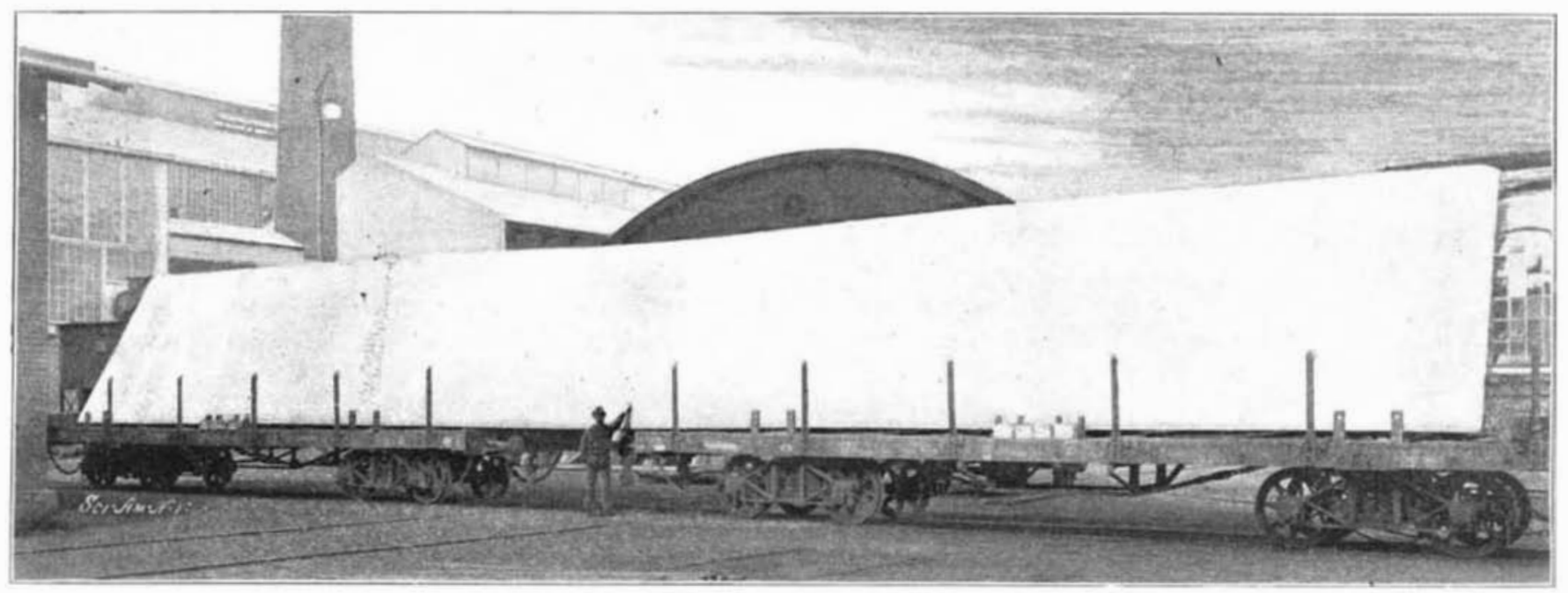

SINGLE SHEET OF METAL ROLLED AT THE ESSEN WORKS.

other works. The principal plant, the Rheinhausen,
is comparatively new, being built in 1896 . It includes three. furnaces of 14,150 cubic feet capacity each, prothree. furnaces of 14,150 cubic feet capacity each, pro-
ducing from 200 to 225 tons every 24 hours. The furnaces are provided with steam hoists, four Cowper heaters, and produce principally Bessemer and hematite pig iron. An interesting feature in connection
with the plant is the service of the ore, a series of with the plant is the service of the ore, a series of
Brown hoist conveyors electrically driven being used Brown hoist conveyors electrically driven , being used
for transferring the ore from shipboard to the plant The blowing engines are of the vertical compoun type, furnishing 32,000 cubic feet of air per minute, furnace gas which operates an electric motor, two 250 horse power steam engines for operating dynamos, and two compound pumping engines. The other furis the average output of this division of the Krup industries. They include four furnaces at Mülhofen
works, three at Hermanns works, and four at Johannes works, but none are of modern type. nes works, but none are of modern type.
The Germania shipyard, or the Kiel plant as it is
sometimes called, after the name of the city near which it is located, is one of the oldest in Europe. Originally a specialty was made of marine engines and boilers. The present works were located at Gaar-
den, a suburb of Kiel, in 1865, and were leased by the Krupps in 1896, and only purchased last year. Fried rich Krupp realized their value as an adjunct to his
other industries, and since they have been $z$ under the other industries, and since they have been :under the
present control, they have produced marine architecture, not only in battleships, cruisers, and smalle at present in use has a frontage on Kiel Harbor of about 1,300 feet and covers 350 acres of ground, an additional area has been purchased, which is more than double its present capacity. As it is, slips are provided for the construotion of seven vessels at one
time, the slips ranging in length from 377 to 640 feet, time, the slips ranging in length from 377 to 640 feet,
with a width of from 85 to 100 feet. Three others . facilities are such that the largest type of battleship yet planned can be built in the most capacious of these inclosures. They represent the latest idea in con-
struction, the lower portion being of concrete with mania yard are the Lloyd ships "Bonn" and "Halle," also the famous "Kaiser Wilhelm der Grosse," which
has made such a record in trans-Atlantic service. The enlargement of this yard, carried out as planned The enlargement of this yard, carried out as planned
by the late Friedrich Alfred Krupp, will make it probably the greatest shipbuilding plant in the world and give it facilities for turning out more than twice the tonnage which its former capacity represented, as a considerable portion of the present works will be
rebuilt. It will cover an area of 600 acres, and employ about 3,000 more men than the old yard, when all of the new shops are in operation. Most of the improvements have been completed. industries described are the proving groun with the nance at Meppen, laid out in connection with the Essen works, also the Gruson works. It is here that the tests have been made which have given the Krupp guns such a reputation among military experts, owing
to the elaborate and costly trials, which have not only to the elaborate and costly trials, which have not only
included ordnance, but projectiles and armor plate. included ordnance, but projectiles and armor plate.
Sections of every kind of armor plate manufactured to fill orders are carried to these grounds and attacked lery is also tested at one of the proving grounds before being sent away from the works.

\section{THE DECAY OF METALS.}

By J. T. Milton, M. Inst. C. E., and W. J. Larke. THE durability of metals under the conditions in which they were actually used is of great importance engineers as questions of strength or cheapness. Copper, brass, gun-metal, and other alloys were chosen for use on account of their durability; but even these metals were sometimes found to corrode or decay under seemingly obscure conditions. It was to cases of such

that this paper is devoted.
The following examples of the decay referred to are adduced:

1. The pitting of the tubes of marine surface-con-

2 . The decay of brass or yellow-metal bolts in com-
densers.

* Abstract of a paper presented before Institution of Civil Engineers. did not account for the corrosion and decay of condenser-tubes which were made of an alloy not having
a duplex structure; nor did it explain why cast irọn in some cases did not decay, even although its composition and structure were the same as where decay took place.

Condenser-tubes were usually made of an alloy consisting of, nominally, 70 per cent copper and 30 per than 70 per cent copper and 1 per cent tin, the remainder being of zinc; while one of the large mail steamship companies, as the result of considerable experience, had the tubes made of 78 per cent copper, 21 .

(nomerial copper and zinc were rarely pure. If the impurities alloy it would still be homogeneous, but if they had a tendency to segregate, as it was well known some of uniformity as might set up local galvanic action and lead to local pitting or corrosion. Segregation wa in the original casting but might also occur whilo the metal was at a high temperature during the while the of annealing, which was several times repeated in thie course of the drawing process. drawing process woult cause the impure portions to be much elongated in the direction of the tube's length, and the resulting corrosion would be seamy; whereas if it occurred alse to a marked degree during anneal-
ing, the corrosion would affect more rounded areas. Examination of the insides of condenser-tubes revealed it was seen that the general surface of the inside of the tubes had become partially dezinckified to an extent sufficient to cause it to crack when the tube is flattened.

In order to determine whether the various impurities which are commonly present in copper-zinc alloys do tend to segregate or diffuse during annealing some experiments, detailed in an appendix, were made. the changes of structure which Muntz metal, and also the 70 to 30 copper-zinc alloy underwent, due to Considerable protection is given to copper-zinc alloys, 